\title{
Improvement of early arthritic symptoms with Pawanmuktasana anti-rheumatic series
}

\begin{abstract}
Arthritis is a common term that is used to describe conditions that results in joint inflammation. These conditions are still the major public health concern as it causes greatest impact on morbidity and costs enormous healthcare expenditure. Studies have showed that performing Yoga significantly improve pain, disability index and general wellbeing. This review mainly focuses on arthritic symptoms can be alleviated by pawanamuktasana (anti rheumatic series).
\end{abstract}

Keywords: pawanmuktasana, joint pain, arthritis, pathophysiology, yoga

\author{
Volume 2 Issue 2 - 2017
}

\author{
Komathi Selvarajah, Kesawan Arumugam \\ 'Faculty of Medicine, AIMST University, Malaysia \\ 2Ministry of Health, Malaysia
}

Correspondence: Komathi Selvarajah, Faculty of Medicine, AIMST University, Malaysia, Tel +60 I2395705 I,

E-mail srkomathi@gmail.com

Received: May 17, 2017 | Published: June 28, 2017

\section{Introduction}

Arthritis is defined as the inflammation that occurs at more than one joint. ${ }^{1}$ The causes of arthritis depend on the form of arthritis. These includes, degenerative arthritis (leading to osteo arthritis), inflammatory arthritis (causing rheumatoid arthritis, psoriatic arthritis, ankylosing spondylitis, juvenile idiopathic arthritis and systemic lupus erythematosus), infective arthritis (septic arthritis) and metabolic arthritis (gout and pseudogout). The major symptoms of arthritis include limited function and pain at the joints. ${ }^{2}$ Management of arthritic condition remains a great challenge to clinicians despite of advancement in health care sectors. ${ }^{3,4}$ Globally, an estimated $22.7 \%$ (54.4 million) of adults had doctor-diagnosed arthritis, with high prevalence in women $(23.5 \%)$ than in men $(18.1 \%)$. The prevalence increased with age. ${ }^{5}$ Arthritis foundation predicted more than 78 million people are expected to be diagnosed to have arthritis by the year 2040 .

The arthritis condition share similar pathophysiological changes at joint region. Many factors like infection, co-morbidities, environmental, trauma, stress and hereditary factors can cause joint damage and contribute to the trigger of immune an inflammatory response through synovial and endothelial cell activation. This mechanism leads to chronic inflammatory by which patient presents with symptoms like pain, joint swelling, redness and reduced range of movement. ${ }^{6}$

Recent Studies conducted at University of California at Los Angeles Medical Center have proved that there is positive effect on chronic arthritis. In another study which was conducted at Pennsylvania showed performing asanas causes significant reductions in pain and noticeable improvements in joint stiffness among osteoarthritis patient. ${ }^{7}$

The practice of asanas in Yoga system commences with Pawanmuktasana series. Right practice of Pawanamuktasana provides flexibility in the joints and removes the muscle stiffness. ${ }^{8}$ Etymologically this word Pawanmuktasana is composed of three Sanskrit words: pawan meaning 'wind' or 'air' mukta, 'liberation' or 'freedom' and asana, 'posture'. ' Pawanmuktasana basically refers to series yoga poses that involves the whole joint regions from head to toe which release air in the body. Adopting a regular practice of asana makes the body physically and mentally fit. It restores vigor and enhances the quality of life. ${ }^{10}$

\section{Diagnosis arthritis}

Clinical evaluation of arthritic pain basically starts with a comprehensive history, physical examination, laboratory testing and diagnostic x-ray films. Patients usually present with pain at one or multiple joints. The pain usually characterized by an intermittent, dull aching or throbbing that may worse with restricted movement of the joint. It can be associated with stiffness as well. Patients may express depressive symptoms as a squeal of the chronic debilitating state of arthritis. ${ }^{11}$

On physical examination tenderness can be elicited along the joint line and surrounding tissues. Range Of Movement decreased as a result of pain or pathologic changes. Inflammatory sign and symptoms like warmth, swelling, effusions, and stress pain, may be present. Untreated Long term arthritic patient may end up with muscle wasting and weakness. ${ }^{12}$

\section{Management}

The primordial goals of treatment in arthritic patient are to relief pain, improvement in joint function and prevention of joint damage. These are achieved with both pharmacologic and non-pharmacologic therapeutic modalities. Thus the management is effective when it includes physical measures to reduce joint loading, an appropriate exercise regimen, medications, and, occasionally, surgery. Patient awareness and education is essential. ${ }^{13}$

Pharmacological treatments reduce inflammation and modulate the autoimmune response and secondly help to modulate the pain response. The common drugs that are used to treat arthritic symptoms include; simple analgesics; non-steroidal anti-inflammatory drugs (NSAID), Disease modifying anti-rheumatic-drugs (DMARD's) and corticosteroids. ${ }^{14}$ Studies has showed that although drugs noticed to give better outcome clinically and radiologically ,however long term drug therapy raise concerns regarding cardiovascular risk and other complications. ${ }^{15}$ 
With regard to non-pharmacological management, many clinical trials have proved that exercise programs may improve pain and function. ${ }^{16,17}$ As such performing yoga particularly pawanmuktasana series provide complete benefit to musculoskeletal system and helps to reduce pain, disability and improves the quality of life of the patients. Studies have also proved that patient who performs pawanmuktasana shows lower levels of pro inflammatory cytokine and immunological markers. ${ }^{18,19}$

\section{Discussion}

Despite years of practicing yoga, many fail to observe any changes due to weight and stiffness at joint which restrict the proper alignment and stretch of various postures. In case of pawanmuktasana it is very easy to perform by anyone at any time or at any place. Moreover it is cost effective and does require costly equipment to practice.

These anti rheumatic series can be performed at home or office at just in sitting position. It is evident that there is no pressure or excess weight exerted on the joint. Thus joints are mobilized safely to stimulate the circulation, secretion and absorption of synovial fluid. This mechanism improves the process of lubrication and simultaneously revitalizes the tissues around the joints. Elimination of toxic gases reduces the degenerative changes due to normal or abnormal activity.

Regular practice of pawanmuktasana brings steady and progressive improvement on any disease ranging from diabetes to hypertension or even from constipation to cancer or any other kind of illness. ${ }^{20}$ Regular practice of pawanmuktasana brings steady and progressive improvement on any disease ranging from diabetes to hypertension or even from constipation to cancer or any other kind of illness. It is recommended to perform these series asana for ten times at each position with periodic rest in between two or three asanas. The details and steps are given within the book on Asana Pranayama Mudra Bandha, by swami satyanandha saraswathi from page 21-44. The asana in each group should be performed in the order given. ${ }^{8}$ Daily practice of pawanmuktasana parts over a period of months brings about a profound benefit for the entire psycho-physiological structure it is advisable to learn the steps and alignment of the posture form the train personnel's. Long term practice of these anti rheumatic series proven to reduce the typical rheumatic symptoms. ${ }^{17-20}$ Proper practice with mindfulness on posture and movement at joint position creates suppleness at joints, relaxes stiff muscles and allows the escape of trapped gases within the joint. Thus increase the joint flexibility and gives mobility and subsequently reduces the joint inflammatory symptoms. ${ }^{21}$

\section{Conclusion}

In summary, pawanmuktasana is a carefully designed series of asana which anybody can practice without worsening the existing ailment. It is evident that regular practice of pawanmuktasana tones muscles, eases the mobility of joint and improves venous circulation around the joints. Healthy lifestyle and diet also plays key role in alleviating arthritic symptoms. This review presented the brief note regarding the effectiveness of pawanmuktasana anti-arthritic series in controlling early symptoms of arthritis and improving the overall quality of life by alternative way.

\section{Acknowledgements}

I would like to express my colleques Ms. Nur Adilla who have inspired me to review this wonderful topic. I also would like to convey my gratitude to my husband and yoga friends who have guided throughout this review.

\section{Conflict of interest}

The author declares no conflict of interest.

\section{References}

1. William C. Arthritis. USA: Medicine net; 2017.

2. Catherine BD. emedicineheallth, USA: 2017.

3. Mody GM, Cardiel MH. Challenges in the management of rheumatoid arthritis in developing countries. Best Pract Res Clin Rheumatol. 2008;22(4):621-641.

4. National health interview survey. Estimated and projected number of adults with doctor-diagnosed arthritis in the United States; 2015.

5. Victor RP, Ronald RW. The Mediterranean Diet \& arthritis. Elsevier, USA: Academic Press; 2014. 698 p.

6. Bernstein S. Practicing yoga regularly can reduce pain, increase flexibility, improve function and lower stress. Georgia: Arthritis Foundation;.

7. Satyananda S. Pawanmuktasana. Asana Pranayama Mudra Bandha. India: Yoga Publications Trust; 1969. $21 \mathrm{p}$.

8. Satyananda SS. Asana Pranayama Mudra Bandha. India: Bihar School of Yoga; 2008.

9. Baird CL. First-line treatment for osteoarthritis. Part 1: Pathophysiology, assessment and pharmacologic interventions. Orthop Nurs. 2001;20(5):17-24.

10. Balaji PA, Varne SR, Ali SS. Physiological effects of yogic practices and transcendental meditation in health and disease. $N \mathrm{Am} \mathrm{J} \mathrm{Med} \mathrm{Sci.}$ 2012;4(10):442-448.

11. Nicholas AD, Vitaly G. Treatment of patients with arthritis-related pain. $J$ Am Osteopath Assoc. 2004;104(S8):2S-5.

12. Baer AB. The Approach to the Painful Joint. Medscape; 2016.

13. Nice guideline. Rheumatoid arthritis: the management of rheumatoid arthritis in adults. UK: NICE; 2009.

14. Kidd BL, Richard ML, Wodehouse T. Current approaches in the treatment of arthritic pain. Arthritis Research \& Therapy. 2007;9:214.

15. Orlova EV, Karateev D, Denisov L, et al. Comparative efficacy of two exercises programs in patients with early rheumatoid arthritis: 6-month randomized controlled trial. Ann Rheum Dis. 2015;74(S2).

16. Daien CI, Hua C, Combe B, et al. Non-pharmacological and pharmacological interventions in patients with early arthritis: a systematic literature review informing the 2016 update of EULAR recommendations for the management of early arthritis. RMD Open. 2017;3(1).

17. Chawla R, Mahajan B, Thakur G, et al. Efficacy of yoga based regimen for treatment of rheumatoid arthritis - a one year study. Int J Ayu Alt Med. 2015;3(2):101-108.

18. Woodyard C. Exploring the therapeutic effects of yoga and its ability to increase quality of life. Int J Yoga. 2011;4(2):49-54.

19. Chawla R, Aparna, Singh B, et al. The clinical significance of one year of yoga practice on biochemical, Immunological and inflammatory markers in rheumatoid arthritis Patients. Int $J$ recent scientific research. 2015;6(12):7982-7986.

20. Singh VK, Bhandari RB, Rana BB. Effect of yogic package on rheumatoid arthritis. Indian J Physiol Pharmacol. 2011;55(4):329-335.

21. Gupta A, Awasthi HH. A critical review of clinical application of yogasanas W.S.R. To Pavanamuktasana. IAMJ. 2004;2(6):1088-1098. 